\title{
Family therapy research: a challenge and a proposal
}

\author{
Bryan Lask, Consultant Psychiatrist, Hospital for Sick Children, Great Ormond Street, \\ London WCl
}

The question is often asked: "Does family therapy work?" This is an important but useless question. It is important because an enormous amount of time, energy and money is put into the clinical practice of family therapy. It is practised in every continent; there are many training courses and qualifications in very many countries, and there are over 40 journals devoted to families and family therapy. Yet there is a healthy and justified scepticism. So yes, we ought to ask whether it works.

But it is also a useless question - as useless as asking "Does surgery work?", "Does medicine work?" or "Does psychiatry work?" More useful questions would be: "Is gastrectomy the best treatment for a gastric ulcer?", or "Is penicillin the treatment of choice in pneumococcal pneumonia?", or "Is lithium a useful prophylactic in manic-depressive disorder?". We could apply the same principles to any of the treatments we use for any of the disorders we meet in child psychiatric practice.

Returning to family therapy, there are many different schools of family therapy which have at least one common factor - the conceptual focus is on the whole family rather than the individual. The schools include structural, strategic, psychodynamic, communications, experiental, transgenerational etc. And, given that family therapy is used for a wide range of presenting problems, more useful questions would be, for example, "Is structural family therapy more effective than strategic family therapy for school refusal?", or "Which of structural family therapy, strategic family therapy or antidepressant medication is most effective for school refusal?". Equally we might ask which form of family therapy is most useful for specific family dysfunctions such as enmeshment, conflict detouring, unresolved grief, or communication problems?

Such questions are clinically relevant, and we may have strong opinions, but truthfully we do not know the answers. There have been sadly few outcome studies that fulfil basic criteria for satisfactory research design. Those carried out in the 1960 s and 1970s, have been reviewed elsewhere. ${ }^{1}$

In the last ten years more studies have been reported, although very few emanate from a child psychiatry base. Black \& Urbanowicz ${ }^{2}$ found that family therapy focused on bereavement counselling is of more value to bereaved families than no intervention. Lask \& Matthew $^{3}$ compared two groups of children with poorly controlled asthma one group receiving conventional medication plus increased attention from a paediatrician; the other receiving medication plus family therapy, focused on family structure and communication. The family therapy group did significantly better on a variety of respiratory function tests at one year follow-up. The study was replicated in Sweden $^{4}$ with similar findings.

Bennun $^{5}$ compared a strategic and problemsolving approach for 20 families with a range of presenting problems in different age groups. Families in both groups achieved favourable changes in their presenting symptoms, but the families treated strategically also showed a significant improvement in family functioning. Russell and colleagues ${ }^{6}$ have compared family therapy and individual supportive therapy for anorexia and bulimia nervosa. Family therapy was found to be more effective at one year follow-up in patients whose illness was not chronic and which had begun before the age of 19 .

The remaining studies have been carried out in adult psychiatric settings and are concerned with the value of family-oriented treatments for schizophrenia. These have been fully reviewed by Berkowitz: ${ }^{7}$ each study shows a significant and often impressive difference in favour of family orientated rather than individual treatments.

The trend, therefore, seems to indicate that certain forms of family therapy are of considerable value in specified conditions. However, there are methodological problems in most outcome studies, these included, and further research is obviously necessary. Why is this not forthcoming?

It would seem that the methodological problems are awesome. Professional lifetimes have been devoted to attempting to construct scales, instruments, schedules and questionnaires, sufficiently valid, reliable, and robust, but sensitive enough to measure family interaction and change. Even if we focus only on individual change and alleviation of symptoms, the methodological purists would insist that outcome studies should fulfil various criteria:

(a) the exact nature of the form of family therapy being tested should be both clearly described and reproducible by other clinicians 
(b) there should be a clear differentiation between non-specific elements, such as those that facilitate and maintain motivation, and specific interventions designed to change targeted family interaction

(c) the symptomatic manifestations of the presenting problems should be measured

(d) control groups should be matched for age, sex, family size and structure, severity and quality of presenting problem, length of therapy, and experience of therapist

(e) outcome measures should be clearly defined and made independently of the therapist

(f) follow-up should be long-term.

The view has been expressed that family therapists should evaluate their work - in principle a fair point, in practice an unrealistic one. Outcome research needs time, energy, finance, resources and skill. Experience suggests that clinicians would have considerable difficulty satisfying the requirements of the formal methodology of behavioural sciences.

So now the time has come to ask, why aren't the very active and skilled researchers in our profession, and particularly in child psychiatry, taking up the challenge of evaluating family therapy? The issues are complex but researchers in child psychiatry have overcome the most formidable obstacles, and have certainly not left such important tasks to their clinical colleagues.

Rather than asking the child psychiatrist on the Isle of Wight in the 1960s to carry out a community survey, a high powered research team carried out the most impressive epidemiological survey. ${ }^{8}$ Schools in Southwark were not expected to compare themselves; another high powered research team did that. ${ }^{9}$ The same applied to maladjusted children in the schools of Newcastle, ${ }^{10}$ and so it goes on.

And if their answer is that the issues are too complex, perhaps they should lower their expectations. Methodological idolatory is a counterproductive religion and the over-emphasis on the need for objectivity, validity, reliability, standardisation and statistical significance may prevent us finding answers to relatively straightforward questions such as "Is this therapist successful with this technique for this problem?" Since we cannot expect any study in this area to be truly adequate, we must accept what we can get, and not be too cavalier in rejecting modest studies" "Empirical beggars cannot be methodological prigs".

After all, if we consider the null hypothesis "research has no value" - there has not been, to my knowledge, a project specifically designed to refute it. Yet research carries on regardless!
We should remember the criticism of a recent president of the paediatric section of the Royal Society of Medicine who said that "Child psychiatrists are unduly preoccupied with epidemiology - they should have a sociology training and become politically active".

Many years ago a very fine paediatrician, John Apley, ${ }^{12}$ stated: "For many years there has been a flirtation between child psychiatry and paediatrics. It is high time they were married, if only for the sake of the children". So now, this leap year, on behalf of family therapy, I say to the brilliant researchers in child psychiatry "Stop hiding your skills on the Isle of Wight, and in the back streets of Camberwell or Waltham Forest; you've done a wonderful job in the schools of Southwark and Newcastle. You've had your fun - now it's time to settle down, for the sake of the children and their families".

\section{References}

${ }^{1}$ LASK, B. (1979) Family therapy outcome research 1972-78. Journal of Family Therapy, 1, 87-92.

${ }^{2}$ BlaCk, D. \& UrbanOWICZ, M. (1987) Family intervention with bereaved families. Journal of Child Psychology \& Psychiatry, 28, 467-476.

${ }^{3}$ LASK, B. \& MATTHEW, D. (1979) Family therapy for poorly controlled childhood asthma: a follow-up study. Archives of Diseases in Childhood, 54, 116-117.

${ }^{4}$ Gustafson, N. el al. (1983) Family therapy for asthmatic children. Journal of Psychosomatic Research, 30, 369-374.

${ }^{5}$ BENNUN, I. (1986) Evaluating family therapy: a comparison of the Milan and problem-solving approaches. Journal of Family Therapy, 8, 235-242.

${ }^{6}$ Russell, G., SZMuCKLER, G., DARE, C. \& EWLer, I. (1987) A trial of family therapy for anorexic and bulimia nervosa. Archives of General Psychiatry, 44, 1047-1056.

${ }^{7}$ BERKOWITZ, R. (1988) Family therapy for schizophrenia and depression. Journal of Family Therapy, 10, (In press).

${ }^{8}$ RutTer, M., Tizard, J. \& Whitmore, K. (eds) (1981) Education, Health and Behaviour. New York: Krieger, Huntington.

9 _- Maughan, B., Mortimore, P., Ouston, J. \& Smith, A. (1979) Fifteen Thousand Hours: secondary schools and their affect on children. London: Open Books.

${ }^{10}$ Kolvin, I., Garside, R., Nicol, A., MacMillan, A., Wolstenholme, F. \& Keitch, I. (1981) Help Starts Here. London: Tavistock Press.

${ }^{11}$ FrUDE, N. (1980) Methodological problems in the evaluation of family therapy. Journal of Family Therapy, 2, 29-44.

${ }^{12}$ A pley, J. (1971) Their question to us.... Clinical Paediatrics, 10, 135-137.

A full list of references is available on request from the author. 